\title{
Embedded Adaptive Mutation Evolutionary Programming for Distributed Generation Management
}

\author{
Muhammad Fathi Mohd Zulkefli ${ }^{1}$, Ismail Musirin², Shahrizal Jelani ${ }^{3}$, Mohd Helmi Mansor ${ }^{4}$, \\ Naeem M. S. Honnoon 5 \\ 1,2,5Faculty of Electrical Engineering, Universiti Teknologi MARA Malaysia,Shah Alam, Selangor, Malaysia \\ ${ }^{3}$ Faculty of Engineering, Technology and Built Environment, UCSI University, Kuala Lumpur, Malaysia \\ ${ }^{4}$ Department of Electrical Power Engineering, College of Engineering, Universiti Tenaga Nasional, Selangor, Malaysia
}

\begin{tabular}{l}
\hline \hline Article Info \\
\hline Article history: \\
Received Nov 9, 2018 \\
Revised Jan 2, 2019 \\
Accepted Mar 18, 2019 \\
\hline
\end{tabular}

Keywords:

Adaptive mutation

Distributed generation

Embedded optimization

Evolutionary programming

\begin{abstract}
Distribution generation (DG) is a widely used term to describe additional supply to a power system network. Normally, DG is installed in distribution network because of its small capacity of power. Number of DGs connected to distribution system has been increasing rapidly as the world heading to increase their dependency on renewable energy sources. In order to handle this high penetration of DGs into distribution network, it is crucial to place the DGs at optimal location with optimal size of output. This paper presents the implementation of Embedded Adaptive Mutation Evolutionary Programming technique to find optimal location and sizing of DGs in distribution network with the objective of minimizing real power loss. 69Bus distribution system is used as the test system for this implementation. From the presented case studies, it is found that the proposed embedded optimization technique successfully determined the optimal location and size of DG units to be installed in the distribution network so that the real power loss is reduced.
\end{abstract}

Copyright $\odot 2019$ Institute of Advanced Engineering and Science. All rights reserved.

\section{Corresponding Author:}

Shahrizal Jelani,

Faculty of Engineering,

Technology and Built Environment,

UCSI University, Kuala Lumpur, Malaysia.

Email: shahrizal@ucsiuniversity.edu.my

\section{INTRODUCTION}

Nowadays, a lot of power companies interested in using distributed generation (DG) in planning for the power system network expansion [1-3]. This is a new trend that happening since the past ten years as many technologies of DG have been introduced by the scientists and engineers. Moreover, the initiatives given by the governments in promoting the use of renewable energy sources in electrical power generation also contribute to the increment number of DG in distribution network. DG is found to be more flexible in handling the sudden increase of demand compared to conventional generation [4-6]. Installation of DG needs to be located at suitable location as the energy produced by the DG, otherwise it will affect the stability of distribution network. Besides that, the presence DG cannot be fully utilized if it is located at non-optimal location.

For the past fifteen years, there have been a lot of studies and research on optimal location and sizing of DG in distribution system. These studies are done to avoid over-compensation and undercompensation by the DG. Besides that, optimal DG installation also focused on operation cost minimization 
$[7,8]$ real power losses minimization $[9,10]$. The DG technologies consist of modular generators which have some benefits to the distribution network [11]. For example, it can produce fewer cost for electricity but higher power reliability with lower environmental consequences [12-14]. Moreover, with the use of DG can increase the reliability on the distribution network. The centralized power plants have their own disadvantages. One of the problems is the transmission distance issue which leads to power losses [15-17]. Recently, utilities have continuously planning on the expansion of their distribution and transmission networks to cater the increment of electrical power demand. The development of new substations or extension of those officially existent is a typical and conventional solution. The conventional solution can be replaced by DG installation approach. DG units can be installed at any areas in the distributed network to supply their power locally or at the points of demand. DG also help in reducing the production cost of thermal generating units by supporting or taking over the thermal generating units $[18,11]$.

Many optimization techniques have been introduced to solve DG installation problem. These include to find the optimal location with fixed size, fixed location with optimal size and both optimal location and size [19]. Evolutionary programming (EP) has been popularly used to solve power system problems including DG installation problem [20]. EP has been used to solve unit commitment problem (UCP) [21], economic dispatch problem [22-24]. = EP offers high accuracy of solution and less computational time [25-27].

Since the early improvement of evolutionary optimization, adaption has dependably been an issue of research and various approach with various levels and sorts of adaptation have been proposed. Numerous analysts are concentrating on taking care of improvement issues by utilizing adaptive techniques, e.g., probability matching, adaptive pursuit method, numerical optimization, and graph colouring algorithms [12, 13]. Basically, the main type of parameter setting consists of parameter tuning and parameter control. Parameter tuning intends to set the reasonable parameters before the keep running of algorithm and the parameters stay consistent amid the execution of calculations. Parameter control intends to appoint beginning values to parameters and after that these values adaptively change amid the execution of calculations [12].

This paper presents the Embedded Adaptive Mutation Evolutionary Programming for Distributed Generation Management. In this study, the Adaptive Mutation has been embedded into the original EP technique to become a new optimization approach. The proposed technique solved on the 69-Bus Distribution System has revealed its capability in managing the DG installation and planning.

\section{METHODOLOGY}

In this section, the implementation of Embedded Adaptive Mutation Evolutionary Programming for Distributed Generation Management is explained in details. The overview of the implementation is illustrated in Figure 1.

The optimization starts with the initialization process. In this process, the decision variables are randomly generated with respect to their constraints and the objective function. For this DG installation problem, location and size of DG are the decision variables. While the objective function is real power loss equation that is minimized in this optimization process. The real power loss is calculated using the randomized values of decision variables and load flow solution. The real power loss is calculated using the following equation:

$$
P_{\text {loss }}=\sum_{i=1}^{n} \sum_{j=1}^{n}\left[\alpha_{i j}\left(P_{i} P_{j}+Q_{i} Q_{j}\right)+\beta_{i j}\left(Q_{i} P_{j}-P_{i} Q_{j}\right)\right]
$$

Where:

$$
\begin{aligned}
& \alpha_{i j}=\frac{r_{i j}}{V_{i} V_{j}} \cos \left(\delta_{i}-\delta_{j}\right) \\
& \beta_{i j}=\frac{r_{i j}}{V_{i} V_{j}} \sin \left(\delta_{i}-\delta_{j}\right)
\end{aligned}
$$

$n$ is the bus number, and $P_{i}, Q_{i}, P_{j}$ and $Q_{j}$ are active and reactive power injections at buses $i$ and $j$, respectively.

The starting point of the optimal search is found by finding the real power loss prior to the DG installation. It is ensured that the real power loss produced after DG installation is less than before DG is installed. The individuals that produced from the initialization process than stored in a pool called as parents pool. Subsequently, minimum value of decision variable, $x_{\min }$ and maximum value of decision variable, $x_{\max }$ are found from the parent's pool. At the same time, the fitness value (which is real power loss) is 
evaluated before the mutation process. Mutation process is a stage where the parents individuals are mutated to produced new generation called offspring. Equation (4) is used to produce offspring together with the Adaptive Mutation.

$$
x_{i+j}=x_{i, j}+N\left[0, \beta\left(x_{j \max }-x_{j \min }\right)\left(\frac{f_{i}}{f_{\max }}\right)\right]
$$

Where $x_{i+j}, x_{i, j}, \beta, x_{j \max }, x_{j \min }, f_{i}, f_{\max }$ are the offspring, parent, search step $(0 \sim 1)$, max parent, min parent, current fitness and max fitness respectively. Equation (4) is supported by equation (5) and equations (6) of adaptive mutation.

$$
\begin{aligned}
& X_{\text {new }, i}=X_{\text {old }, i}+\left(X_{\text {old }}^{\max }-X_{\text {old }}^{\min }\right) X_{i} \\
& \text { If } X_{\text {new }}>X_{\text {old }}^{\text {max }}, X_{\text {new }}=X_{\text {old }}^{\max }
\end{aligned}
$$

Where $X_{i}$ generated randomly and the random number is between $(0,0.05)$.

Tuning and control parameters of EP are adjusted by some deterministic administer without utilizing any feedback data from the search space; adaptive adjustment alters the parameters utilizing the feedback data from the search space; and self-versatile adjustment adjusts the parameters by the evolutionary programming itself.

The individuals produced from the mutation process are used to recalculate the fitness of real power loss. Then, the algorithm continues with the combination process which both parents and offspring populations are combined to be a large population of forty individuals. From the forty individuals, twenty best individuals are selected based on their ranking. The best twenty individuals will then undergo convergence test. A stopping criterion is set in order to know whether the optimization process has converged or not. The stopping criterion is the difference between the first individual and the twentieth individual is must be equal or less than 0.0001 , otherwise it will go back to the mutation process and repeat the same processes until converge.

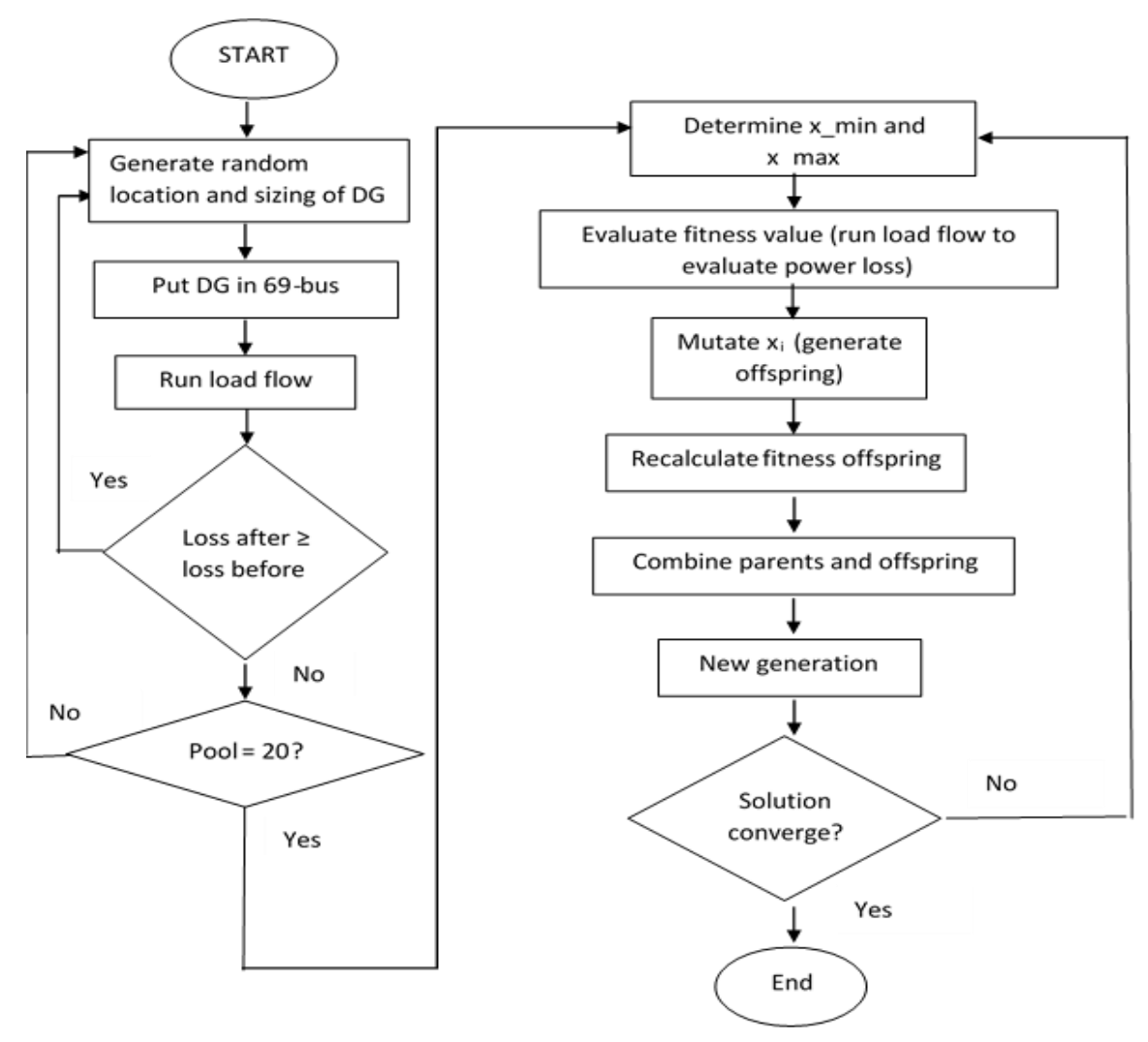

Figure 1. Flowchart for optimal location and sizing DG using embedded adaptive mutation evolutionary programming 


\section{RESULTS AND DISCUSSION}

Results that produced from the implementation of Embedded Adaptive Mutation Evolutionary Programming technique for optimal DG installation in distribution network are tabulated in Table 1, Table 2 and Table 3. These three tables represent three case studies which are one DG, two DG and three DG installations. The results are found from the experiment on the IEEE 69-Bus test system. It can be seen from Table 1 that the optimal location of the one DG unit is at bus 58 for all values of load factor. However, the its size is different for load factor equal to 1 . Based on Figure 1, the real power loss that produced after the one DG unit installation is less than the real power loss before installation. At load factor equal to 1, a decline in real power loss can be observed from $0.4088 \mathrm{MW}$ to $0.1856 \mathrm{MW}$. On top of that, further increment of the load factor by 0.3 up to 2.5 unit stand in need for a bigger size of the DG unit to be at $2.6932 \mathrm{MW}$; even though the location maintained at the bus 58. Furthermore, the average of difference in power loss for load factor of 1.3-2.5 showed a significant value of $0.3485 \mathrm{MW}$ which is greater than the real power for load factor equal to 1 that results in $0.2266 \mathrm{MW}$ of difference in real power loss.

Table 1. Location and sizing of one DG unit

\begin{tabular}{ccc}
\hline Load factor, $\lambda$ & DG sizing & Location \\
\hline 1 & 1.5977 & 58 \\
1.3 & 2.6932 & 58 \\
1.6 & 2.6932 & 58 \\
1.9 & 2.6932 & 58 \\
2.2 & 2.6932 & 58 \\
2.5 & 2.6932 & 58 \\
\hline
\end{tabular}

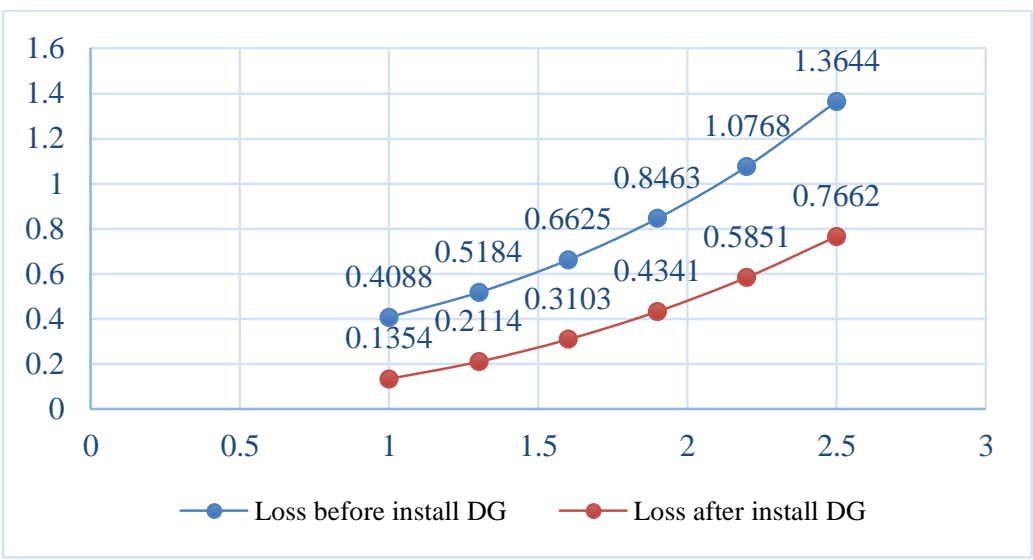

Figure 1. Real power loss before and after installation of DG

Based on Table 2, the optimal location the two DG units are at bus 62 and bus 38 respectively for load factor equal to 1. And their sizes are 1.3919 MW and 4.5035 MW respectively. While for load factor equal 1.3 to 2.5 , their locations are at bus 62 and bus 7 with sizes of $1.6220 \mathrm{MW}$ and $0.7106 \mathrm{MW}$ respectively. Similar to the first case study, it can be seen from Table 2 that the real power loss has also reduced after the installation of two DG units using the proposed embedded optimization technique.

Table 2. Location and sizing of two DG units

\begin{tabular}{ccccc}
\hline $\begin{array}{c}\text { Load } \\
\text { factor, } \boldsymbol{\lambda}\end{array}$ & \multicolumn{2}{c}{ DG sizing $(\mathrm{MW})$} & \multicolumn{2}{c}{ Location (Bus no.) } \\
$\mathrm{DG}_{1}$ & $\mathrm{DG}_{2}$ & $\mathrm{Lo}_{1}$ & $\mathrm{Lo}_{2}$ \\
\hline 1 & 1.3919 & 4.5035 & 62 & 38 \\
1.3 & 1.6220 & 0.7106 & 61 & 7 \\
1.6 & 1.6220 & 0.7106 & 61 & 7 \\
1.9 & 1.6220 & 0.7106 & 61 & 7 \\
2.2 & 1.6220 & 0.7106 & 61 & 7 \\
2.5 & 1.6220 & 0.7106 & 61 & 7 \\
\hline
\end{tabular}




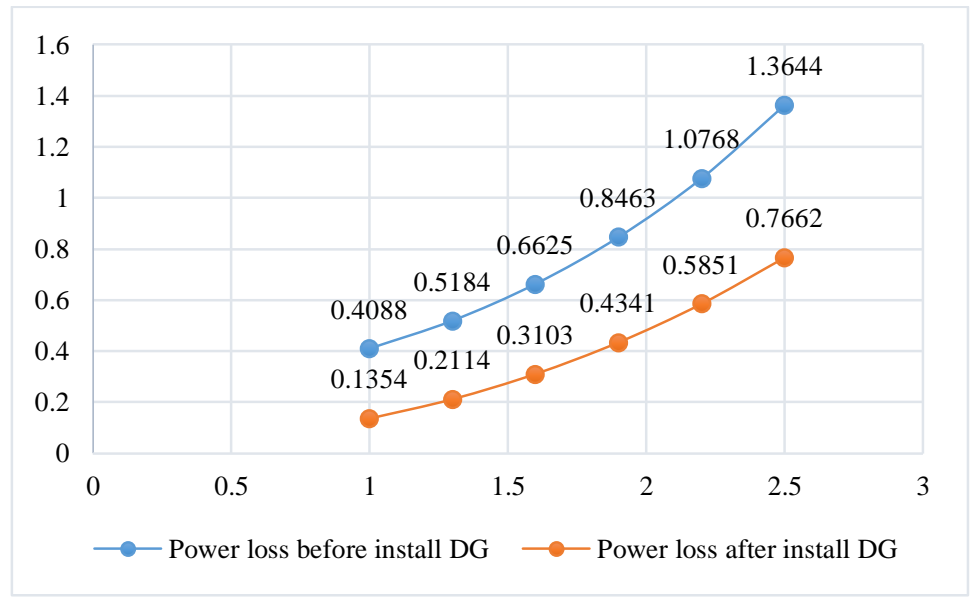

Figure 2. Real power loss before and after installation of two DG units

From Table 3, it can be seen that the location and size of the three DG units are maintained for all values of load factor which are at bus 29 , bus 10 and bus 61 with sizes of $0.9217 \mathrm{MW}, 1.6220 \mathrm{MW}$ and $0.7106 \mathrm{MW}$ respectively. Referring to Figure 3, the allocation of all three DG are fixed throughout every implement of the load factor which are: bus 29 (DG 1), bus 10 (DG 2), and bus 61 (DG 3). Their sizes also the same which are $0.9217 \mathrm{MW}, 1.6220 \mathrm{MW}$ and $0.7106 \mathrm{MW}$ for DG 1, DG 2 and DG 3 respectively. Moreover, the value of changes of real power loss before and after the instalment of all three DG units have the same result with the value obtained by installing two DG units in the network system.

Table 3. Location and sizing of three DG units

\begin{tabular}{ccccccc}
\hline $\begin{array}{c}\text { Load } \\
\text { factor, } \lambda\end{array}$ & \multicolumn{3}{c}{ DG sizing (MW) } & \multicolumn{3}{c}{ Location (Bus no.) } \\
\hline 1 & 0.9217 & 1.6220 & 0.7106 & 29 & 10 & 61 \\
1.3 & 0.9217 & 1.6220 & 0.7106 & 29 & 10 & 61 \\
1.6 & 0.9217 & 1.6220 & 0.7106 & 29 & 10 & 61 \\
1.9 & 0.9217 & 1.6220 & 0.7106 & 29 & 10 & 61 \\
2.2 & 0.9217 & 1.6220 & 0.7106 & 29 & 10 & 61 \\
2.5 & 0.9217 & 1.6220 & 0.7106 & 29 & 10 & 61 \\
\hline
\end{tabular}

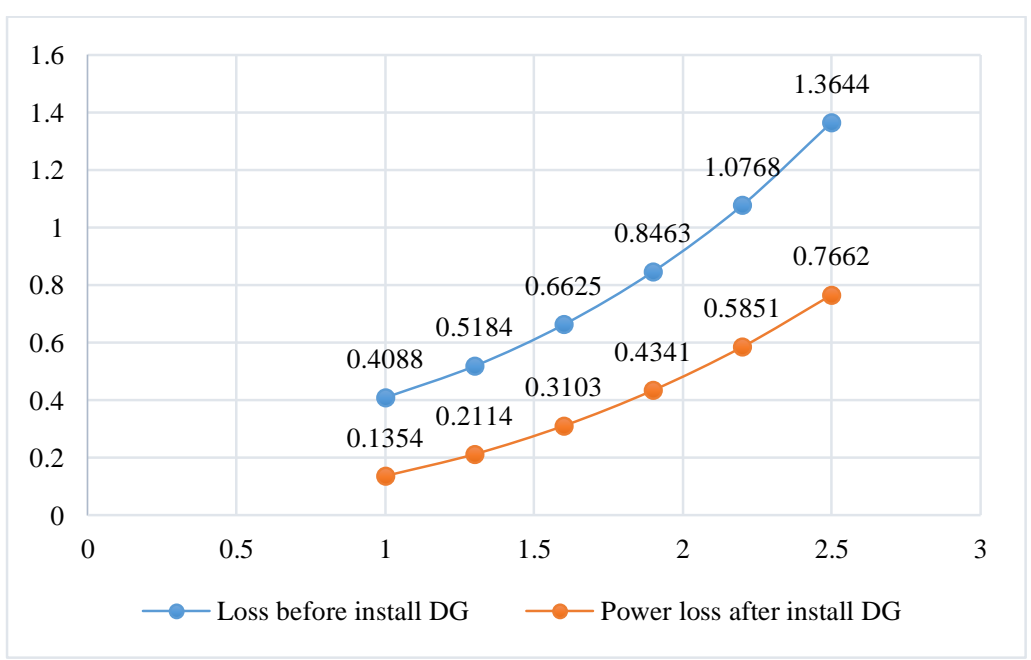

Figure 3. Power loss before and after installation of three DGs 


\section{CONCLUSION}

A new embedded optimization technique that formed from Adaptive Mutation and Evolutionary Programming for DG management has been presented in this paper. From the three case studies of optimal location and size of DG conducted, it can be seen that the proposed embedded technique capable to find the best location and size of DG so that the real power loss of the distribution system is reduced. Adaptive Mutation has helped to improve the quality of offspring produced from the mutation process. This proposed embedded technique is beneficial to grid system operators (GSOs) in planning and managing the penetration of DG into their system.

The proposed embedded technique can be improved by embedding another optimization technique or an operator of the technique to improve the population produced from initialization process. Monte-Carlo technique is one of suitable techniques that can help to increase the fitness of parent's population. Besides that, instead of real power, total production cost, total installation and voltage stability improvement also can be the objective of the DG installation optimization problem. Moreover, the problem also can be solved using multiobjective optimization to satisfy more than one objective at a time.

\section{ACKNOWLEDGEMENT}

The authors would like to acknowledge The Institute of Research Management and Innovation (IRMI) UiTM, Shah Alam, Selangor, Malaysia and Ministry of Higher Education (MOHE) for the support of this research. This research is supported by Ministry of Higher Education (MOHE) under the Fundamental Research Grant Scheme (FRGS) with project code: 600-RMI/FRGS 5/3 (0102/2016).

\section{REFERENCES}

[1] M. Bavafa, "A new method of Evolutionary programming in DG planning," Proc. - 2011 Int. Conf. Energy, Autom. Signal, ICEAS - 2011, no. x, pp. 828-831, 2011.

[2] S. Saha and V. Mukherjee, "Optimal placement and sizing of DGs in RDS using chaos embedded SOS algorithm," IET Gener. Transm. Distrib., vol. 10, no. 14, pp. 3671-3680, 2016.

[3] L. Rosa, M. Louro, B. Almeida, F. Gonçalves, A. M. Rodrigues, and J. Ferreira Pinto, "Distributed generation at distribution system level resilience to voltage dips - a real case," CIRED - Open Access Proc. J., vol. 2017, no. 1, pp. 1703-1706, 2017.

[4] T. Ackermann, "Distributed generation- a definition .pdf," vol. 57, pp. 195-204, 2001.

[5] B. A. De Souza, S. Member, and J. M. C. De Albuquerque, "Optimal Placement of Distributed Generators," Ieee Proceeding, 2006.

[6] K. M. Muttaqi, A. D. T. Le, M. Negnevitsky, and G. Ledwich, "An algebraic approach for determination of DG parameters to support voltage profiles in radial distribution networks," IEEE Trans. Smart Grid, vol. 5, no. 3, pp. 1351-1360, 2014.

[7] G. Celli and F. Pilo, "Optimal distributed generation allocation in MV distribution networks," pp. 81-86, 2002.

[8] W. El-Khattam, K. Bhattacharya, Y. Hegazy, and M. M. A. Salama, "Optimal investment planning for distributed generation in a competitive electricity market," IEEE Trans. Power Syst., vol. 19, no. 3, pp. 1674-1684, 2004.

[9] K. Nara, Y. Hayashi, K. Ikeda, and T. Ashizawa, "Application of tabu search to optimal placement of distributed generators," no. C, pp. 918-923, 2002.

[10] T. K. A. Rahman, S. R. A. Rahim, and I. Musirin, “Optimal Allocation and Sizing of Distributed,” 2016, pp. 1520.

[11] L. Mokgonyana, J. Zhang, H. Li, and Y. Hu, "Optimal location and capacity planning for distributed generation with independent power production and self-generation," Appl. Energy, vol. 188, pp. 140-150, 2017.

[12] M. F. Alhajri and M. R. Alrashidi, “Distribution Generation Sizing in Distribution Networks,” Ieee Proceeding, pp. 2-8, 2010.

[13] S. Dorahaki, "Optimal DG Placement with the Aim of Profits Maximization," Indones. J. Electr. Eng. Comput. Sci., vol. 1, no. 2 , p. $249,2016$.

[14] R. J. Flores, B. P. Shaffer, and J. Brouwer, "Dynamic distributed generation dispatch strategy for lowering the cost of building energy," Appl. Energy, vol. 123, pp. 196-208, 2014.

[15] A. Kaviani-Arani, "Optimal Placement and Sizing of Distributed Generation Units Using Co-Evolutionary Particle Swarm Optimization Algorithms," TELKOMNIKA Indones. J. Electr. Eng., vol. 13, no. 2, 2015.

[16] C. Ma, P. Kaufmann, J. C. Töbermann, and M. Braun, "Optimal generation dispatch of distributed generators considering fair contribution to grid voltage control," Renew. Energy, vol. 87, pp. 946-953, 2016.

[17] J. A. Martín García and A. J. Gil Mena, "Optimal distributed generation location and size using a modified teaching-learning based optimization algorithm,” Int. J. Electr. Power Energy Syst., vol. 50, pp. 65-75, 2013.

[18] L. Mehigan, J. P. Deane, B. P. Ó. Gallachóir, and V. Bertsch, "A review of the role of distributed generation (DG) in future electricity systems," Energy, vol. 163, pp. 822-836, 2018.

[19] M. Pesaran H.A, P. D. Huy, and V. K. Ramachandaramurthy, "A review of the optimal allocation of distributed generation: Objectives, constraints, methods, and algorithms," Renew. Sustain. Energy Rev., no. October, pp. 1-20, 2016. 
[20] D. B. Fogel, "What is evolutionary computation?," IEEE Spectr., vol. 37, no. 2, pp. 26-32, 2000.

[21] E. S. Ali, S. M. A. Elazim, and A. Y. Abdelaziz, "Ant Lion Optimization Algorithm for optimal location and sizing of renewable distributed generations," Renew. Energy, vol. 101, pp. 1311-1324, 2017.

[22] M. H. Mansor, M. R. Irving, and G. A. Taylor, "A decomposition/aggregation method for solving electrical power dispatch problems," in 2012 47th International Universities Power Engineering Conference (UPEC), 2012, pp. 17.

[23] E. J. Contreras-Hernández and J. R. Cedeño-Maldonado, “A self-adaptive evolutionary programming approach for power system state estimation,” Midwest Symp. Circuits Syst., vol. 1, pp. 571-575, 2006.

[24] P. J. A. L. J. Fogel and D. B. Fogel, "An Evolutionary Programming Approach to Self-Adaptation on Finite State Machines,” Proc. Fourth Int. Conf. Evol. Program., pp. 355-365, 1995.

[25] Hong-Tzer Yang, Pai-Chuan Yang, and Ching-Lien Huang, "Evolutionary programming based economic dispatch for units with non-smooth fuel cost functions," IEEE Transactions on Power Systems, vol. 11, no. 1. pp. 112-118, 2002.

[26] N. Kumarappan and M. R. Mohan, "Fuel restricted short term economic dispatch using evolutionary programming for utility system," Int. J. Electr. Power Energy Syst., vol. 25, no. 10, pp. 821-827, Dec. 2003.

[27] I. Musirin and T. K. A. Rahman, "Evolutionary programming optimization technique for solving reactive power planning power system," WSEAS Trans. Inf. Sci. Appl., vol. 2, no. 5, pp. 495-500, 2005. 